Phosphate buffer at $\mathrm{pH} 8.0$ gave the sharpest staining reactions, although there was little difference at $\mathrm{pH} 7.0$ or $\mathrm{pH} 7.5$. As the buffer $\mathrm{pH}$ was increased above $\mathrm{pH} 8.0$ staining with both substrates became progressively weaker, especially above $\mathrm{pH}$ 9.0. Below pH 7.0 staining with $\alpha$-naphthyl butyrate became weaker, and below $\mathrm{pH} 5.0$ staining with naphthol AS-D chloroacetate began to disappear.

This work was supported by a Medical Research Council project grant. I thank Professor FGJ Hayhoe for valuable advice.

References

' Gomori G. Chloroacyl esters as histochemical substrates. J Histochem Cytochem 1953;1:469-70.
${ }^{2}$ Rozenszajn L, Leibovich M, Shoham D, Epstein J. The esterase activity in megaloblasts, leukaemic and normal haemopoietic cells. Br J Haematol 1968; 14:605-19.

${ }^{3}$ Hayhoe FGJ, Quaglino D. Haematological cytochemistry. Edinburgh: Churchill Livingstone, 1980.

${ }^{4} \mathrm{Li}$ CY, Lam KW, Yam LT. Esterases in human leucocytes. $J$ Histochem Cytochem 1973;21:1-12.

s Yam LT, Li CY, Crosby WH. Cytochemical identification of monocytes and granulocytes. Am J Clin Pathol 1971;55:28390.

- Armitage RJ, Linch DC, Worman CP, Cawley JC. The morphology and cytochemistry of human T-cell subpopulations defined by monoclonal antibodies and $\mathrm{Fc}$ receptors. $\mathrm{Br} \mathrm{J}$ Haemato 1983;51:605-13.

Requests for reprints to: Dr DM Swirsky, Department of Haematological Medicine, University Clinical School, Hills Road, Cambridge CB2 2QL, England.

\section{Simple technique to identify haemosiderin in immunoperoxidase stained sections}

\section{CAROLE D NICKOLS Department of Morbid Anatomy. The London Hospital, Whitechapel, Lon- don $E 11 B B$}

Identifying iron compounds in immunoperoxidase stained sections usually presents little or no problem to the trained eye. The distinction between peroxidase positive staining and haemosiderin becomes important when one is in doubt as to which compound is giving the "brown positive" result.

Recent biopsies have presented this problem. Although naturally occurring endogenous peroxidase activity has been blocked in the sections there has been confusion between the brown staining of haemosiderin and the positive brown staining of the 3-3' diaminobenzidine tetrahydrochloride, especially in weakly positive sections.

The staining of serial sections with haematoxylin and eosin and by Perls' Prussian blue is routinely performed when this problem arises. But unless a comparator microscope is used to check the identity of the stained cell, the problem remains. Counterstaining the peroxidase stained slide with Perls' Prussian blue technique, however, permits the identification of the two compounds on the same slide.

\section{Material and methods}

Sections were cut from biopsy specimens of surgically removed pituitary gland which had beero embedded in paraffin and fixed in formalin. Ten $3 \mu \mathrm{m}$ serial sections were prepared and dried in $37^{\circ} \mathrm{C}$ incubator for $12 \mathrm{~h}$.

The immunoperoxidase staining method used was an adaptation of the method of Kovacs et al. ${ }^{\prime}$ The method differed from the original technique by using antihuman prolactin antiserum (Mercia Brocades) at a dilution of $1 / 1000$ (diluent $0.15 \mathrm{M}$ phosphate buffered saline, $\mathrm{pH} 7 \cdot 2$ ) at $4^{\circ} \mathrm{C}$ for $1 \mathrm{~h}$ on material obtained from surgical biopsies. Before staining, the natural endogenous peroxidase activity was blocked using the modified technique that Slocombe $e t \mathrm{al}^{2}$ used in the demonstration of blood group antigens.

After treatment with $1 \%$ osmium, the last stage of the original technique before mounting the section, the sections were gently washed in running tap water for $5 \mathrm{~min}$. They were then washed several times in distilled water. The original technique of Perls ${ }^{3}$ heated potassium ferrocyanide and $1 \%$ hydrochloric acid-was then applied to show the haemosiderin in the section.

The Perls' Prussian blue and the uncounterstained peroxidase serial slides were compared with the peroxidase section counterstained with Perls' Prussian blue using a Zeiss comparison bridge mounted on two Zeiss Standard 18 microscopes. (Carl Zeiss (Oberkochen) Limited) 
Results

The three slides of the serial sectioned materialperoxidase uncounterstained, Perls' Prussian blue, and the peroxidase counterstained with Perls' Prussian blue-were carefully compared by matching the architecture of the fields using a comparison bridge. Neither the prolactin nor the haemosiderin components seemed to be diminished as a result of the extra staining procedure.

Low background staining resulted from the use of reasonably fresh potassium ferrocyanide crystals; the background staining appeared to increase in proportion to the increased shelf life of the crystals, although this was not measured histoquantitatively. But distinction could still be made between the peroxidase positive staining and the haemosiderin.

The increased time in washing after the osmium treatment, when performed with care, did not seem to increase the fragility of the sections, although more vigorous washing for longer periods was not attempted.

\section{Discussion}

Hormone identification plays an important part in the diagnosis of pituitary adenomas. Often, biopsy specimens obtained from surgically removed pituitary gland contain sites of old haemorrhage which are sparse, diffuse, and intermingled with the hormone producing cells. At the sites the differentiation between hormone and haemosiderin must be clear, which is why the technique was originally evaluated.
It has previously been used successfully after the peroxidase-antiperoxidase method of Sternberger and Cucullis ${ }^{4}$ in renal cell carcinoma, ${ }^{5}$ where large amounts of iron pigment were present in the section.

With the increased use of immunoperoxidase techniques in surgical pathology, ${ }^{6}$ the addition of this simple but old technique to the modern one could further increase its specificity.

I thank Mr Ken Swettenham and Professor Berry for encouragement and help with this paper.

\section{References}

' Kovacs K, Corenblum B, Sirek AMT, Penz G, Ezrin C. Localization of prolactin in chromophobe pituitary adenomas: study of necropsy material by immunoperoxidase technique. J Clin Pathol 1976; 29:250-8.

${ }^{2}$ Slocombe GW, Berry CL, Swettenham KV. The variability of blood group antigens in gastric carcinoma as demonstrated by the immunoperoxidase technique. Virchows Arch (Pathol Anat) 1980;387:289-300.

${ }^{3}$ Perls Von M. Nachweis von Eisenoxyd in gewissen Pigmenten. Virchows Arch (Pathol Anat) 1867;39:42-8.

4 Sternberger LA, Cucullis JJ. Method for enzymatic intensification of immunocytochemical reaction without use of labelled antibodies. J Histochem Cytochem 1969;17:190.

${ }^{5}$ Lindop GBM, Fleming S. Renin in renal cell carcinoma-an immunocytochemical study using antibody to pure human renin. J Clin Pathol 1984;37:27-31.

- Taylor CR, Kledzik G. Immunologic techniques in surgical pathology-a spectrum of "new" special stains. Hum Pathol 1981;12:590-6.

Requests for reprints to: Miss CD Nickols, Department of Experimental Pathology, Institute of Pathology, The London Hospital, Whitechapel, London E1 1BB, England.

\section{Storage of skin biopsies at $-70^{\circ} \mathrm{C}$ for future fibroblast culture}

\author{
KJ FOWLER Birth Defects Research Institute, Royal \\ Children's Hospital Research Foundation, \\ Parkville, Victoria 3052, Australia
}

It is difficult to know when to establish fibroblastic cell cultures from paediatric necropsies. Newborn babies who seem to have defects due to chromosome aneuploidy may die before the results of lymohocytic karyotypes are known. Lysosomal storage diseases requiring confirmation by enzyme assay on cultured cells may be suspected only when microscopical examination of tissues has been completed. Establishing a culture from every necropsy is expensive. A simple method of storing a tissue sample for subsequent culture would be useful in these circumstances and would also have other practical uses in a clinical cytogenetics or tissue culture laboratory-for example, when samples are delivered at inconvenient times.

The cryoprotective effect of glycerol on frozen spermatozoa was reported in 1949.' This resulted in many techniques which describe the storage of frozen mammalian cells and tumours. ${ }^{2-4}$ In 1959, dimethyl sulphoxide was used to prevent the haemolysis of frozen red blood cells. ${ }^{5}$ Five years later Lehr et l $^{6}$ described the successful transplantation of skin autografts which had been previously frozen using cryoprotective agents.

We report here a simple method of storing skin biopsies $\left(2-3 \mathrm{~mm}^{3}\right)$ at $-70^{\circ} \mathrm{C}$ in culture medium plus dimethyl sulphoxide for 15-23 days without loss of capacity for fibroblastic cell growth. 